\title{
Retrospective analysis of prevalence of rickets and associated factors among children admitted to pediatric ward in jimma university specialized hospital
}

\begin{abstract}
Background: Rickets is the disease of growing bone that is unique to children and adolescents. It is caused by a failure of osteoid to calcify in growing person. It commonly occurs due to inadequate sunshine exposure, vitamin D deficiency, dietary deficiency of calcium and phosphorus. It is highly prevalent in Ethiopia in about $41 \%$ of children with five years and below with frequent combination with protein energy malnutrition and infectious diseases.
\end{abstract}

Objective: to assess the prevalence of rickets and associated factors among children admitted to pediatric ward of Jimma University specialized hospital from May 1,2010 to April 30, 2013. Methods and materials: A facility based cross sectional retrospective analysis of patients' record with rickets admitted to pediatric ward of Jimma University Specialized Hospital from May 1, 2010 to April 302013 was conducted and data were collected using structured questionnaire by trained five data collectors and analyzed using SPSS version 16, chisquare test was used to test association between variables with confidence interval of $95 \%$ and the association accepted as significant if $\mathrm{p}$-value is $<0.05$. Data were presented by using texts, tables and figure.

Results: A total of 170 rachitic children were studied from total of 1620 admitted children revealing $10.5 \%$ of rickets prevalence rate. Type of breast feeding $(\mathrm{X} 2=24.99, \mathrm{P}<0.001)$, duration of breast feeding $(\mathrm{X} 2=6.19, \mathrm{P}=0.013)$, time of complementary food introduction $(\mathrm{X} 2=24.99, \mathrm{P}<0.001)$ and in adequate sunshine exposure $((\mathrm{X} 2=82.4, \mathrm{P}<0.001)$ were factors that are associated with Rickets.

Conclusion and Recommendation: The prevalence of rickets was high and associated with type and duration of breast feeding, time of complementary food introduction and in adequate sunshine exposure indicating the need for Health education on sunshine exposure and breastfeeding issues.

Keywords: rickets, prevalence, associated factors, children
Volume I Issue 7 - 2014

\author{
Chala Kenenisa,' Haimanot Ewnetu, ${ }^{2}$ \\ Habtamu Sime ${ }^{3}$ \\ 'Department of Health officer, Jimma University, Ethiopia \\ 2Department of Epidemiology, Jimma University, Ethiopia \\ ${ }^{3}$ Department of pediatrics, Jimma University, Ethiopia
}

Correspondence: Haimanot Ewnetu, Department of Epidemiology, Jimma University, Jimma, Ethiopia, Tel 252000000000, Email hewnetu@yahoo.com

Received: September 29, 2014 | Published: November 21,

\section{Introduction}

Rickets is a disease of growing bone that is unique to children and adolescents. It is caused by failure of osteoid to calcify in a growing person. Failure of osteoid to calcify in adult is called osteomalacia. Vitamin D deficiency rickets occur when the metabolites of vitamin $\mathrm{D}$ are deficient. Less commonly, dietary deficiency of calcium and phosphorus may also results in rickets. Vitamin D3 (cholecalciferol) is formed in the skin from derivative of cholesterol under the stimulus of ultraviolet B light. Ultraviolet B light or cod liver oil was the significant sources of vitamin $\mathrm{D}$ until early in the $20^{\text {th }}$ century when ergo sterol (vitamin D2) was synthesized from irradiated plant steroids. During the industrial revolution, rickets appeared in epidemic form in temperate zone where the pollution from factories blocked the sun's ultraviolet rays. Thus rickets was probably the first childhood disease caused by environmental pollution.

Natural nutritional source of vitamin D are limited primary to fatty ocean going fish, dairy milk fortified with vitamin D (400IU/L)human milk contains little vitamin D generally less than 20-40IU/L. Therefore, infant who are breast fed are at risk for rickets, especially those who have darkly pigmented skin, which blocks penetration of ultra- violet light. ${ }^{2}$ Rickets usually manifested by frontal bossing, craniotabes, delayed closure of fontanelles, knobby deformities, bowlegs, knocked knee, Harrison's groove, rachitic rosary and others. ${ }^{3}$ Usually rickets is difficult to reverse once it occur but we can avoid further complication by vitamin D (600,000IU stat) supplementation and prevent by early exposure to sunshine ad giving vitamin $\mathrm{D}$ rich diet for breast feeding child and pregnant ladies if possible all reproductive age group women. ${ }^{4}$

In Britain $30 \%$ of immigrants from Indian subcontinent and the West Indies were found to have rickets and the figure rise to $74 \%$ when biochemical findings were included in the study. ${ }^{5}$ Rickets is quite prevalent in Ethiopia and $41 \%$ of children age five year and less than their age and is commonly associated with protein energy malnutrition, infectious diseases of various cause including respiratory tract, anemia, congestive heart failure and gastrointestinal tract risk recurrent diarrhea and mal absorption. ${ }^{6}$

\section{Aim}

The aim of this study is to determine the prevalence of rickets and associated factors in children admitted to Jimma University specialized hospital from May 1, 2010 to April 30, 2013. 


\section{Methods and materials}

\section{Study Setting and Participants}

The study was conducted in JUSH pediatric ward which is located in Jimma town, $352 \mathrm{~km}$ southwest of Addis Ababa, the capital city, from April 1 to 30, 2014. Retrospective analysis of the patient records was conducted by revising the clinical charts of patients admitted to pediatrics department of JUSH with rickets from May 1, 2010 to April 30,2013 . The source populations are all pediatric patients admitted to JUSH during May 1, 2010 to April 30, 2013 and study populations are all patients diagnosed to have rickets and admitted to the pediatrics department of JUSH during the abovementioned period.

\section{Data collection process}

Chart of patients admitted with rickets at pediatric ward of JUSH from May 1, 2008 to April 30, 2013 were revised to extract relevant data using structured data collection format. Data was collected by trained nurses. The questionnaires contain socio demographic characteristics of the mothers/ care givers and children, dietary habit and clinical factors. The dependent variable was prevalence of Rickets while the independent variables included socio demographic, dietary related and clinical variables.

\section{Data analysis}

Data were analyzed using SPSS version 16 statistical software. Chi-square test were used to test the association at $95 \%$ confidence interval and $\mathrm{P}$ - value of $<0.05$ was considered as a cut-off point for statistical significance and presented using tables, graph and descriptions.

\section{Ethical consideration}

Ethical Clearance was obtained from Ethical Review Committee of Jimma University and Jimma University Specialized Hospital and the confidentiality of the information was kept.

\section{Results}

\section{Distribution of rickets among children by socio demo- graphic characteristics}

170 rachitic children who were admitted to pediatric ward of JUSH from May 1, 2010 to April 30, 2013 were studied for prevalence of rickets over a period of three years from 1620 children admitted to pediatric ward revealing about $10.5 \%$ prevalence rate. There was no significant sex difference with females $49.4 \%$ and males $50.4 \%$. Out of them, $97.6 \%$ were within the age range from 3-24 months, while the remaining $2.4 \%$ of them were in the age range from $25-59$ months of age. No cases were observed in infants under 3 months of age and above 59 months of age. Majority of children were ordered as $4^{\text {th }}$ and $5^{\text {th }}$ birth order $41.8 \%$ followed by $2^{\text {nd }}$ and $3^{\text {rd }} 33.9 \%$ as indicated in Table 1. No rachitic children labeled as the first birth order. The children who were exposed to sunlight were $66(38.8 \%)$ and majority of children were exposed sunlight on weekly basis $38(57.6 \%)$ followed by 2-3 days/week, 27(40.9\%) (Table1).

\section{Dietary factors}

A total of 91(58\%) were breastfed for one year or less and 66(42\%) were breastfed for more than one year. Rickets was also found to be higher among children even with longer duration of breast feeding with $\mathrm{X} 2=6.19$ and $\mathrm{P}=0.013$. The majority received their complementary feeding after six months $99(58.2 \%)$ and the rest $71(41.8 \%)$ re- ceived before six months of age. Significant association was found between prevalence of rickets and time of starting complementary feeding with $\mathrm{X} 2=24.99$ and $\mathrm{P}=0.000$ indicating that early introduction of complementary food has a protective effect against rickets. Significant association was observed between rickets and sun shine exposure status with $\mathrm{X} 2=82.4$ and $\mathrm{p}=0.000$ indicating rickets is more likely to occur in children with no sun shine exposure. Significant association was observed with $\mathrm{X} 2=17.01$ and $\mathrm{p}=0.000$ indicating rickets prevalence increases among children as frequency of sunlight exposure decreases (Table 2).

Table I Distribution of rickets in children by social and demographic characteristics in Jimma University Specialized Hospital, Jimma, South West Ethiopia, April 2014

\begin{tabular}{|c|c|c|c|c|}
\hline \multirow{2}{*}{$\begin{array}{l}\text { S. } \\
\text { No }\end{array}$} & \multirow{2}{*}{ Variables } & & \multicolumn{2}{|c|}{ Prevalence of rickets } \\
\hline & & & Frequency & Percentage \\
\hline \multirow{3}{*}{ I } & \multirow{3}{*}{ Age of children } & 3-24 month & 98 & 57.6 \\
\hline & & $25-59$ month & 72 & 42.4 \\
\hline & & total & 170 & 100 \\
\hline \multirow{3}{*}{2} & \multirow{3}{*}{ Sex } & male & 86 & 50.6 \\
\hline & & female & 84 & 49.4 \\
\hline & & total & 170 & 100 \\
\hline \multirow{5}{*}{3} & \multirow{5}{*}{$\begin{array}{l}\text { Order of the } \\
\text { child }\end{array}$} & Ist & 21 & 12.3 \\
\hline & & 2nd and $3 r d$ & 58 & 33.9 \\
\hline & & 4th -5 th & 71 & 41.8 \\
\hline & & $>6$ th & 30 & 18 \\
\hline & & total & 170 & 100 \\
\hline \multirow{3}{*}{4} & \multirow{4}{*}{$\begin{array}{l}\text { Exposure to sun } \\
\text { light }\end{array}$} & yes & 66 & 38.8 \\
\hline & & no & 104 & 61.2 \\
\hline & & total & 170 & 100 \\
\hline \multirow{4}{*}{6} & & daily & I & 1.5 \\
\hline & \multirow{3}{*}{$\begin{array}{l}\text { Exposure } \\
\text { frequency }\end{array}$} & $2-3$ days $/ w$ & 27 & 40.9 \\
\hline & & weekly & 38 & 57.6 \\
\hline & & total & 66 & 100 \\
\hline \multirow{3}{*}{7} & \multirow{3}{*}{ Sunlight hours } & $<$ l hour & 46 & 70 \\
\hline & & $>1$ hour & 20 & 30 \\
\hline & & total & 66 & 100 \\
\hline
\end{tabular}

\section{Distribution of rickets among children with clinical} conditions

Concerning clinical condition widening of wrist was found in $69 \%$ of cases at all age groups and all cases that had craniotabes were under 6 months of age, while the frequencies of other physical signs were variable (Figure 1). As indicated in table below from the total of 170 studied rachitic children, $58 \%$ were also diagnosed to be under weight, while other $23 \%$ were marasmic, and other $12 \%$ were diagnosed to have kwashiorkor and $34.7 \%$ were anemic (Table 3 ).

\section{Discussion}

Nutritional rickets remains a major health problem for children in many regions of country including Ethiopia. Its etiology and pathogenesis is thought to be multi factorial. ${ }^{1}$ This study revealed that rickets is prevalent among studied children with prevalence rate of $10.5 \%$. This is almost the same to the result obtained by a case control study conducted in Addis Ababa at Ethio-Swedish children's hospital. ${ }^{7}$ This study found that there is significant association between rickets and sunshine exposure status $(\mathrm{p}=0.000)$ indicating higher prevalence of rickets in children with no sun shine exposure which is comparable 
with a case control study carried out in Kuwait. This is because vitamin D production in the skin is by product of sun shine exposure. ${ }^{8}$

This study also revealed that breast feeding $(\mathrm{p}=0.000)$ and duration of breast feeding $(\mathrm{p}=0.013)$ were associated with rickets indicating higher prevalence among children who breastfed exclusively and for longer duration. This finding is similar to the result of a study carried out in Vander-berg to assess prevalence of rickets in infant. This can be attributed to that exclusively breast fed children and children breast fed for longer duration are more likely to not feed other sources of Vitamin D like fishes, milk and eggs and also human milk contains a vitamin D concentration of $<25 \mathrm{IU} / \mathrm{L}$ making it a low source of vitamin D. ${ }^{9}$

Table 2 Association between prevalence of rickets and different dietary and social factors of children in Jimma University Specialized Hospital, Jimma town, South West Ethiopia, June, 20I4

\begin{tabular}{|c|c|c|c|c|c|c|}
\hline \multirow{2}{*}{ S. No } & \multirow{2}{*}{ Variables } & & \multicolumn{2}{|c|}{ Prevalence of Rickets } & \multirow[t]{2}{*}{$\times 2$} & \multirow[t]{2}{*}{$\mathrm{P}$} \\
\hline & & & Frequency & Percentage & & \\
\hline \multirow{3}{*}{ I } & \multirow{3}{*}{$\begin{array}{l}\text { Type of } \\
\text { breastfeeding }\end{array}$} & Exclusive & 138 & 81.2 & 24.99 & $<0.001$ \\
\hline & & Nonexclusive & 32 & 18.8 & & \\
\hline & & Total & 170 & 100 & & \\
\hline \multirow{3}{*}{2} & \multirow{3}{*}{$\begin{array}{l}\text { Duration of } \\
\text { breast feeding }\end{array}$} & $<12$ months & 76 & 42 & 6.19 & 0.013 \\
\hline & & $>12$ months & 91 & 58 & & \\
\hline & & Total & 170 & 100 & & \\
\hline \multirow{3}{*}{3} & \multirow{3}{*}{$\begin{array}{l}\text { Start of } \\
\text { complementary }\end{array}$} & $<6$ months & 71 & 41.8 & 24.99 & $<0.001$ \\
\hline & & $>6$ months & 99 & 58.2 & & \\
\hline & & Total & 170 & 100 & & \\
\hline \multirow{4}{*}{4} & \multirow{4}{*}{$\begin{array}{l}\text { Exposure to } \\
\text { sunlight }\end{array}$} & Yes & 66 & 38.8 & 82.4 & $<0.001$ \\
\hline & & No & 104 & 61.2 & & \\
\hline & & Total & 170 & 100 & & \\
\hline & & Daily & 1 & 1.5 & 17.01 & $<0.001$ \\
\hline \multirow{3}{*}{5} & Exposure & 2-3/week & 27 & 40.9 & & \\
\hline & frequency & Weekly & 38 & 57.6 & & \\
\hline & & Total & 66 & 100 & & \\
\hline
\end{tabular}

Table 3 Distribution of rachitic children by their clinical nutritional status in Jimma University Specialized Hospital, Jimma town, South West Ethiopia, June, 20I4

\begin{tabular}{lllll}
\hline S. No & Variables & & Frequency & Percentage \\
\hline \multirow{4}{*}{ Nutritional status (Anthropometry) } & Marasmus & 39 & 23 \\
& & Kwashiorkor & 21 & 12 \\
& & Marasmic kwashiorkor & 13 & 7 \\
& & Under weight & 97 & 58 \\
& & Total & 170 & 100 \\
& & Yes & 60 & 34.7 \\
& \multirow{3}{*}{ Anemic } & No & 110 & 65.3 \\
& & Total & 170 & 100 \\
\hline
\end{tabular}

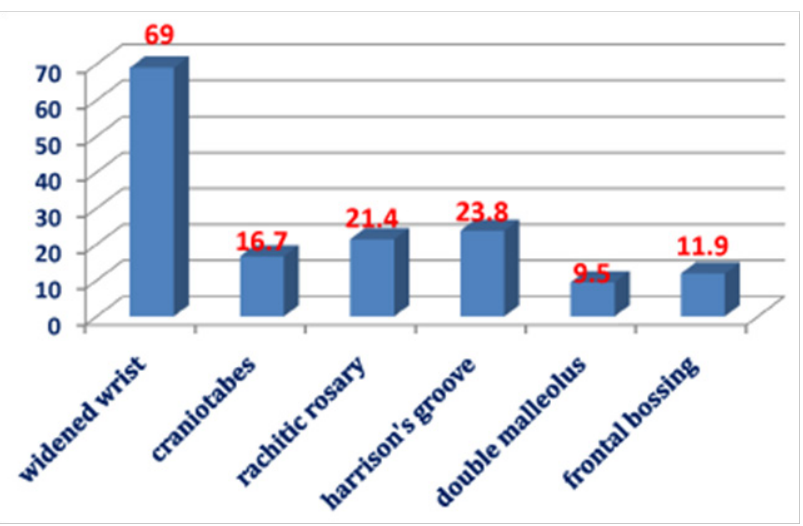

Figure I Clinical presentation of Rachitic children $(n=170)$ in Jimma University Specialized Hospital, Jimma town, South West Ethiopia, June, 2014.

Initiation time of complementary feeding was found to be associated to rickets $(\mathrm{P}=0.000)$ indicating less prevalence among children who started complementary feeding early. This coincides with finding from a case control study carried out in Kuwait which reported that early introduction of complementary food has a protective effect against rickets. This can be because of delayed complementary feeding/prolonged breastfeeding may lead to a breast milk dependent child who prefers milk over complementary food which may not be solely adequate as the age of the child increases more than six months. Nevertheless, the exact age at which to introduce complementary food, duration, appropriate frequency, content and factors affecting intake of complementary food are beyond the scope of the current study and requires further investigation. ${ }^{8}$

This study also identified that most of rachitic children were presented with widened wrist which is same finding to a systematic nutritional survey carried out in Ethiopia. It may be because of it is easy sign to pick out for it is at periphery although it needs further investigation. ${ }^{6}$ Protein energy malnutrition and anemia were identified as common nutritional problems in studied rachitic children which is similar to a case control study conducted at Ethio-Swedish children's hospital in Addis Ababa that reported infectious diseases, PEM, anemia and congestive heart failure as common associated conditions. This may be due to most identified associated factors like low socio economic status/care taker is also associated with other poor nutritional status of children but its assessment is beyond scope of this study. ${ }^{7}$ 


\section{Conclusion}

This study found that the prevalence of rickets is high. Prolonged exclusive breast feeding, inadequate or absence of sun shine exposure, delayed initiation of complementary food were associated with rickets. Most of the rachitic children studied were presented with widened wrist and frequency for other clinical findings varies. Protein Energy malnutrition and Anemia were some of the nutritional problems identified associated with rickets in studied children.

\section{Acknowledgements}

We acknowledge Jimma University for financing the study. We thank Jimma University Specialized Hospital for providing us the data.

\section{Conflicts of interests}

The authors declare that they have no competing interests regarding the publication of this article.

\section{Funding}

None.

\section{References}

1. Curran JS, Barness LA. Nutrition. In: Behrman R, Jenson B, Kleigman R (Eds.), Nelson text book of pediatrics, W.B. Saunders Company, Philadelphia, London. 2010;:84-187.
2. Tefera B. Vitamin D deficiency. In: B Tefera (Eds.), Lecture note on nutrition, Addis Ababa, Birhanu selam. 2007:132-169.

3. Bereket A. Rickets in developing countries. In: Hochberg Z (Ed.), Vitamin D and Rickets. Karger AG, Medical and Scientific Publishers Basel, Switzerland. 2003;6:220-232.

4. Lawrence M, Gartner MD, Greer FR. Prevention of rickets and vitamin D deficiency: In New guidelines for vitamin D intake. Pediatrics. 2003;111(4):908-910.

5. Jellite D. Rickets in childhood. In: J Stanfield (Ed.), Diseases of Children in Tropics and Subtropics. 1979.

6. Wondale Y, Shiferaw F, Lulseged S. A systematic review of nutritional rickets in Ethiopia: status and prospects. Ethiop Med J. 2005;43(3):203210

7. Lulseged S. Severe rickets in children's hospital Addis Ababa. Ethiop Med J. 1990;28(4):175-181.

8. Molla AM, Badawi MH, Al-Yaish S, et al. Risk factors for nutritional rickets among children in Kuwait. Pediatr Int. 2000;42(3):280-284.

9. Dagnelie PC, Vergote FJ, van Staveren WA, et al. High prevalence of rickets in infants on macrobiotic diet. Am J Clin Nutr. 1990;51(2):202208 